\title{
Práticas corporais integrativas: proposta conceitual para o campo das Práticas Integrativas e Complementares em Saúde
}

\author{
Integrative mind-body practices: concept proposal for the field \\ of Traditional and Complementary Medicine
}

Priscilla de Cesaro Antunes (https://orcid.org/0000-0003-2739-193X) ${ }^{1}$

Alex Branco Fraga (https://orcid.org/0000-0002-6881-1446) ${ }^{2}$

${ }^{1}$ Universidade Federal de Goiás. Av. Esperança s/n, Chácaras de Recreio Samambaia. 74690-900 Goiânia GO Brasil. pri.antunes@ufg.br ${ }^{2}$ Universidade Federal do Rio Grande do Sul. Porto Alegre RS Brasil.

\begin{abstract}
The Brazilian National Policy on Integrative and Complementary Practices (PNPIC) was published in 2006. Integrative mind-body practices are part of that policy and they are offered in Brazilian health care services. The concept of Integrative Mind-Body Practices is not consolidated in the literature and its use in government documents is imprecise. The article aimed at proposing a definition for that concept based on the experience of groups of Integrative Mind-Body Practices in Primary Health Care in Florianópolis, Brazil, as well as offering an alternative to the problems of registration and monitoring of the PNPIC. The methodology adopted was Grounded Theory (GT) in its interpretative and constructivist perspective, upon which a formal theory was developed. The data were produced through observations of the activities, conversations with professionals, and interviews with users of groups of Yoga, Lian Gong, Qi Gong, and Circular Dances. The data were coded, validated, and analyzed according to GT steps. The process of devising the concept resulted from the interconnection of the meanings ascribed by participants in contrast to the literature. This analysis enabled us to outline the phenomenon and propose a designation aligned with the PNPIC.

Key words Integrative Medicine, Complementary Therapies, Primary Health Care, Grounded Theory
\end{abstract}

Resumo A Política Nacional de Práticas Integrativas e Complementares (PNPIC) foi publicada no Brasil em 2006. As práticas corporais integrativas fazem parte desta política e estão presentes nos serviços de saúde brasileiros. Embora oficializado, o conceito de Práticas Corporais Integrativas não está consolidado na literatura e seu emprego em documentos governamentais é impreciso. Assim, o objetivo deste artigo foi propor uma definição baseada na experiência de grupos de Práticas Corporais Integrativas vinculados à Atenção Básica em Florianópolis-SC, bem como oferecer uma alternativa aos problemas de registro e monitoramento da PNPIC. A metodologia adotada foi a Grounded Theory (GT) - perspectiva interpretativa $e$ construtivista -, sobre a qual uma teoria formal foi desenvolvida. Os dados foram produzidos em observações de atividades, conversas com profissionais e entrevistas com usuárias de grupos de Yoga, Lian Gong, Qi Gong e Danças Circulares, e posteriormente codificados, validados e analisados conforme os passos previstos pela GT. O processo de formulação conceitual resultou da articulação dos sentidos atribuídos pelos participantes em contraste com a literatura. Por meio deste movimento analítico, foi possível delinear o fenômeno $e$ propor uma designação alinhada à PNPIC.

Palavras-chave Medicina Integrativa, Terapias Complementares, Sistema Único de Saúde, Grounded Theory 


\section{Introdução}

O campo das Medicinas Tradicionais e Complementares envolve um conjunto heterogêneo de práticas, saberes e produtos diferentes da medicina convencional ${ }^{1}$. No Brasil, sua institucionalização no Sistema Único de Saúde (SUS) teve como marco a publicação da Política Nacional de Práticas Integrativas e Complementares (PNPIC), na qual atualmente estão contempladas 29 modalidades terapêuticas ${ }^{2-4}$.

Apesar da sua oficialização, estudos têm apontado para a imprecisão no escopo do que pode ser balizado como Práticas Integrativas e Complementares (PICS) nas políticas públicas ${ }^{5-9}$. No caso das práticas corporais, cujas atividades foram as mais ofertadas no SUS entre $2004^{2} \mathrm{e}$ $2017^{5}$, há uma tendência em considerar como PIC aquelas de base oriental, como o yoga, o lian gong, o tai chi chuan, as massagens tui-ná, do in, shiatsu, shantala, o reiki, etc. Curiosamente, caminhadas, ginástica, esportes, etc., às vezes são também mencionadas como PIC.

Documentos oficiais que orientam a implementação de PICS nos serviços de saúde brasileiros apresentam diferentes empregos do termo "práticas corporais", bem como ausência de conceituação até $2018^{10}$. Documento internacional correspondente $^{1}$, publicado pela Organização Mundial da Saúde (OMS) em 2013, contempla algumas destas práticas, mas sem uma definição para o conjunto.

A falta de delimitações sobre o que pode ser considerado PIC no SUS exige atenção porque tem desdobramentos no campo dos saberes e práticas em saúde, uma vez que mobilizam diferentes intencionalidades, metodologias e concepções. Além disso, tem impactos nos registros e monitoramento das PICS, no financiamento e na gestão. Essa preocupação é também do Ministério da Saúde (MS), tendo em vista as tentativas de melhoramento dos sistemas de cadastro ${ }^{11}$ e a publicação do Glossário Temático de PICS $^{12}$.

Diante desse panorama, e visando responder às demandas por delimitação no âmbito nacional, desenvolvemos um projeto de doutorado cujo objetivo foi a formulação do conceito "práticas corporais integrativas"10. Ao revisar a literatura, encontramos estudos que evidenciaram essa necessidade e ensaiaram propostas conceituais $^{13,14}$, mas não como intenção central, como fora na referida tese.

Consideramos nesta pesquisa que um conceito é sempre uma designação de passagem em um dado campo e em cada tempo histórico. Trata- mos, portanto, de realizar uma operação lógica e epistemológica que definisse os fenômenos não como coisas dadas, mas como coisas interpretadas, construídas em confronto sistemático com a realidade, dentro de um quadro teórico historicamente posicionado ${ }^{15}$.

Seguimos a proposição na qual um conceito é formado por três componentes: 1) o recorte da realidade que se quer conceituar, 2) o conjunto de enunciados que o caracterizam, e 3) o nome escolhido para designá-lo ${ }^{16}$. Este artigo, portanto, apresenta a trajetória de formulação de um conceito de "práticas corporais integrativas" e o texto está organizado de modo a contemplar essas três dimensões.

\section{Metodologia}

A investigação priorizou uma abordagem qualitativa orientada pela Grounded Theory (GT) em sua versão interpretativa e construtivista ${ }^{17}$. A GT não tem uma meta-teoria como ponto de partida do processo investigativo, na forma de uma estrutura teórico-analítica estabelecida a priori, pois a formulação de teorias fundamentadas nos dados prospectados é sua principal contribuição às pesquisas qualitativas.

Ao longo da pesquisa, colocamos em ação os princípios da comparação constante, da amostragem e da sensibilidade teórica, bem como os processos de microanálise, codificação e validação dos dados previstos nesta metodologia.

Os dados foram produzidos via observações registradas em diário de campo, entrevistas com usuárias e roda de conversa com condutoras de grupos de práticas corporais integrativas oferecidos na Atenção Básica do município de Florianópolis-SC, todas gravadas e transcritas.

No mapeamento realizado para a pesquisa, encontramos 20 grupos (nove de yoga, cinco de lian gong, quatro de danças circulares e dois de qi gong). A maioria conduzido por profissionais dos centros de saúde ou NASF (três professoras de educação física, duas enfermeiras, um médico, uma fisioterapeuta e um técnico de enfermagem); cinco grupos conduzidos por voluntárias e dois por residentes de educação física. Quanto ao perfil das usuárias, predominavam mulheres brancas de meia idade e idosas.

Depois da aprovação pelo Comitê de Ética em Pesquisa da Universidade Federal do Rio Grande do Sul, visitamos uma vez cada um desses grupos, observamos as aulas e perguntamos às condutoras se conheciam outras práticas cor- 
porais integrativas além da que trabalhavam. Como a resposta das 15 pessoas consultadas foi sim, perguntamos a elas se haveria algo comum em tais práticas. Analisamos as respostas no software NVivo, por frequência, resultando numa "nuvem de palavras" (Figura 1).

Algum tempo depois, convidamos todas as condutoras dos grupos visitados a participar de uma roda de conversa. Das 15, sete compareceram e aceitaram fazer parte da pesquisa, sendo excluídas as demais. Orientamos as profissionais a se reunirem conforme a prática com que trabalhavam. Formou-se uma dupla de danças circulares, uma de Lian Gong e um trio de yoga. Lançamos a questão: como vocês explicariam essa prática para alguém que não a conhece? Após discutirem entre si, cada grupo apresentou na roda sua explicação. Em seguida, perguntamos ao grande grupo: o que vocês acham que estas práticas têm em comum? O que lhes dá sentido de unidade? A nuvem de palavras foi projetada como disparador da discussão.

Por fim, escolhemos o grupo de yoga, o de Lian Gong e o de danças circulares que tinham o maior número de praticantes, e entrevistamos cinco usuárias de cada, selecionadas pelo critério de antiguidade no grupo. A pergunta para estas 15 usuárias foi: se você fosse convidar alguém que nunca participou de uma atividade como essa, como você explicaria o que acontece nas aulas?
Realizamos a análise da empiria mediante três etapas de codificação (inicial, focalizada e teórica). Sistematizamos os dados em códigos e categorias, ampliando gradativamente seu potencial de abstração e escopo, até emergir a teoria da pesquisa, expressa na formulação de enunciados que caracterizam as práticas corporais integrativas.

Adicionalmente, a GT indica a necessidade de validação dos dados como estratégia de rigor para a formulação da teoria fundamentada, em contraste com a realidade estudada. Esse movimento foi mais uma ação para produzir resultados e qualificar a formulação conceitual, confrontando os enunciados produzidos e as representações das usuárias e condutoras dos grupos. Um processo de validação diferente daquele no qual um seleto grupo atesta a verdade sobre a teoria elaborada. O detalhamento desses movimentos analíticos está apresentado na Figura 2.

O produto de pesquisas baseadas em GT pode ser de dois tipos: 1) substantivo, quando uma teoria é gerada a partir de um contexto específico que se aplica somente àquele campo investigado; 2) formal, quando uma teoria gera conceitos abstratos que podem ser aplicados de forma generalizada a uma realidade mais ampla ${ }^{18}$. O foco deste artigo está na apresentação de uma teoria formal, explicitada no conceito formulado de "práticas corporais integrativas".

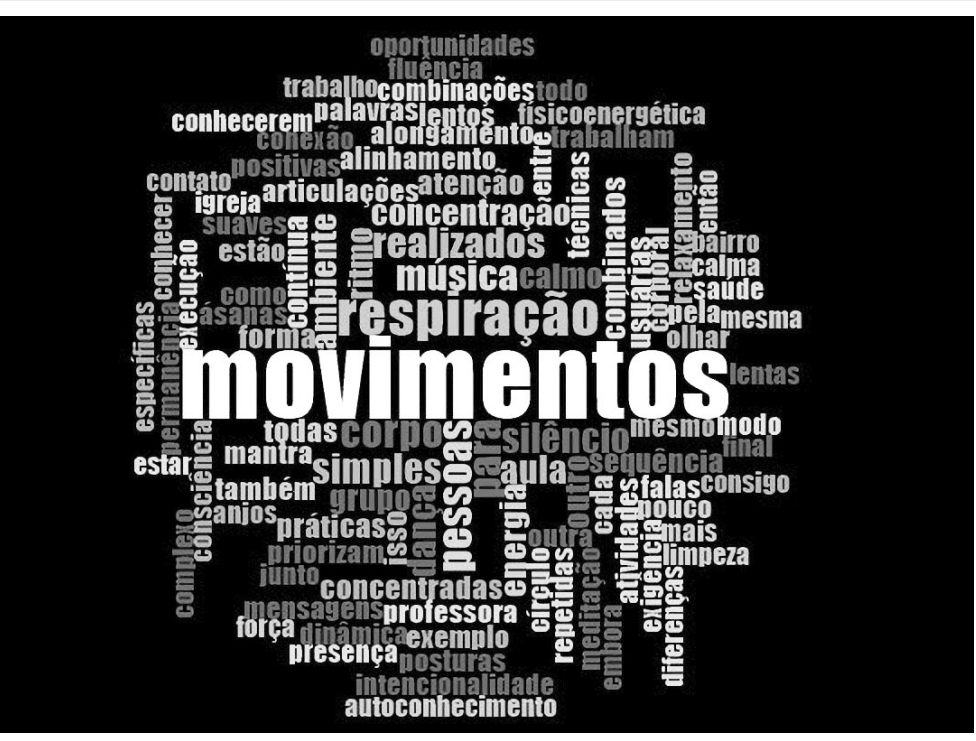

Figura 1. Nuvem de palavras derivada dos dados das condutoras dos grupos. 


\begin{tabular}{|c|c|c|c|}
\hline $\begin{array}{l}\text { Codificação } \\
\text { inicial }\end{array}$ & $\begin{array}{l}\text { Leitura do diário de campo, da transcrição da roda de } \\
\text { conversa e das entrevistas, identificando as frases que } \\
\text { expressavam o conteúdo das falas, na perspectiva da } \\
\text { microanálise. } \\
\text { Estes destaques dos textos foram, manualmente, } \\
\text { organizados a partir de códigos preliminares, por meio de } \\
\text { frequência de respostas e aproximações de significados, e } \\
\text { reunidos sob um mesmo título/categoria. }\end{array}$ & $\begin{array}{l}341 \\
\text { códigos }\end{array}$ & $\begin{array}{l}33 \\
\text { categorias }\end{array}$ \\
\hline $\begin{array}{l}\text { Codificação } \\
\text { focalizada }\end{array}$ & $\begin{array}{l}\text { Estabelecimento de relações entre as categorias, ampliando } \\
\text { seu nível de abstração e abrangência. } \\
\text { A aproximação de seu conteúdo/significado permitiu a } \\
\text { redação de enunciados, tarefa fundamental para elaboração } \\
\text { de conceitos. }\end{array}$ & $\begin{array}{l}19 \\
\text { categorias }\end{array}$ & $\begin{array}{l}72 \\
\text { enunciados }\end{array}$ \\
\hline Validação 1 & \multicolumn{3}{|c|}{$\begin{array}{l}\text { Estes enunciados foram submetidos a primeira validação, a partir da confrontação } \\
\text { com a realidade estudada. } \\
\text { Dos } 20 \text { grupos de práticas corporais integrativas encontrados inicialmente, } 16 \\
\text { estavam ocorrendo neste momento da pesquisa, os quais foram novamente visitados. } \\
\text { O procedimento executado foi ler e apreciar se cada enunciado era capaz de explicar } \\
\text { o que estava sendo observado nas aulas. }\end{array}$} \\
\hline $\begin{array}{l}\text { Codificação } \\
\text { final }\end{array}$ & $\begin{array}{l}\text { A partir das observações, ampliou-se o potencial de } \\
\text { abstração, sintetizando ainda mais a escrita. } \\
\text { Foi possível identificar as características proeminentes no } \\
\text { conjunto de práticas e o que lhes dá sentido de unidade, } \\
\text { apesar da sua diversidade. } \\
\text { Esta ação descritiva permitiu estabelecer a categoria central } \\
\text { da teoria e chegar a um conceito de práticas corporais } \\
\text { integrativas, composto por cinco enunciados. }\end{array}$ & $\begin{array}{l}1 \\
\text { categoria }\end{array}$ & $\begin{array}{l}5 \\
\text { enunciados }\end{array}$ \\
\hline Validação 2 & $\begin{array}{l}\text { Apreciação destes enunciados por um grupo formado por tr } \\
\text { profissionais do SUS, um representante do MS e um professo } \\
\text { renomado na área. } \\
\text { - As participantes do campo de pesquisa foram consultadas } \\
\text { respostas de quatro delas foram gravadas no ato da visita, en } \\
\text { áudio de Whatsapp. } \\
\text { - O retorno do representante do MS foi feito por e-mail e se } \\
\text { relevância da pesquisa e afirmar que os conceitos vigentes no } \\
\text { Temático de PICS, sem avaliação da elaboração conceitual pr } \\
\text { - Quanto ao retorno do professor universitário, embora as tr } \\
\text { quatro meses, com afirmação de aceite por duas vezes, o mes } \\
\text { respostas em tempo para compor a análise. } \\
\text { Assim, a apreciação do conceito se deu com os retornos das } \\
\text { as quais foram solicitadas a avaliar se aquilo que realizavam } \\
\text { trabalhavam se refletia nos enunciados. }\end{array}$ & $\begin{array}{l}\text { ês usuárias e } \\
\text { r universitár } \\
\text { resencialme } \\
\text { quanto uma } \\
\text { imitou a rec } \\
\text { MS são os d } \\
\text { oveniente da } \\
\text { atativas tenh } \\
\text { mo não envi } \\
\text { articipantes } \\
\text { has aulas/con }\end{array}$ & $\begin{array}{l}\text { duas } \\
\text { io } \\
\text { nte, e as } \\
\text { enviou via } \\
\text { onhecer a } \\
\text { o Glossário } \\
\text { pesquisa. } \\
\text { am durado } \\
\text { ou suas } \\
\text { do campo, } \\
\text { n o que }\end{array}$ \\
\hline
\end{tabular}

Figura 2. Movimento analítico: processos de codificação e validação dos dados.

Fonte: Elaborada pela autora. 


\section{Resultados}

\section{$O$ recorte da realidade que se quer conceituar}

Buscamos conceituar neste processo de pesquisa o conjunto de práticas como Lian Gong, Qi Gong, tai chi chuan, lien chi, yoga, danças circulares, biodança, bioenergética, meditação, etc. ofertadas no âmbito do SUS e presentes na PNPIC. Para tanto, discutimos o que há de comum neste conjunto, elencando as convergências que possibilitaram a sistematização de enunciados para a formulação conceitual.

\section{Os enunciados que caracterizam o fenômeno}

O processo de sistematização categorial dos dados resultou na enunciação de uma série de características do fenômeno estudado, conforme apresentamos no Quadro 1, correspondendo ao que foi expresso pelas participantes da pesquisa. As falas das condutoras e usuárias, somadas às observações da pesquisadora, permitiram elaborar 72 enunciados que caracterizam as práticas corporais na perspectiva das PICS, constituindo o suporte empírico para a formulação conceitual.

Após submeter estes enunciados à primeira validação de dados, foi possível estabelecer a categoria central da teoria, denominada "conexão". Este foi o elemento-síntese capaz de congregar a multidimensionalidade categorial dos dados, mostrando-se como o principal atributo das práticas corporais sob a ótica das PICS, que se caracterizam pela conexão:

- do ser humano consigo mesmo, com as outras pessoas, com o universo e com o tempo presente;

- das práticas de saúde com a vida cotidiana, aproveitando a filosofia e os valores que fundam e se disseminam através das práticas, por uma outra ética de viver;

- das dimensões físicas, mentais, emocionais, energéticas e espirituais do corpo, das práticas corporais e dos processos saúde-doença;

- do cuidado com a promoção da saúde, numa visão abrangente e complexa, em favor da ampliação de recursos pessoais e coletivos para lidar com os processos saúde-doença;

- dos métodos científicos com as experiências humanas para explicá-las e transformá-las na proximidade do real, incorporando, inclusive, dimensões imateriais frequentemente subjugadas pela racionalidade instrumental moderna.
No campo da saúde, a noção de conexão apresenta correspondência com o paradigma da vitalidade-energia, eixo de sustentação das PICS, que contrasta com o paradigma da normalidade -patologia, dominante no modelo biomédico. O Quadro 2 traz uma síntese de ambos, feita com base em estudos comparados ${ }^{19-26}$.

No caso das práticas corporais integrativas, esta discussão se faz em torno do movimento humano, que é o seu diferencial frente a outras modalidades terapêuticas. Se essas práticas assumem o paradigma da vitalidade-energia, o movimento humano não pode ser concebido como uma série de repetições mecânicas de gestos técnicos, que considera apenas a funcionalidade orgânica do corpo, cujas principais preocupações se colocam nos parâmetros fisiológicos de frequência, intensidade e duração dos exercícios em busca da regularidade físico-sanitária.

O exercício da negação constitui o primeiro passo para a formulação de um conceito. Nessa linha, as participantes da pesquisa mencionaram que as práticas corporais integrativas não se resumem à noção biológica, ao exercício físico e à performance:

Não é só movimento, trabalham com outra visão de corpo e saúde, além do só biológico, só físico e só repetição de movimentos... é preciso desconstruir essa lógica de aula de ginástica com peso, de trabatho com o corpo fragmentado, peça por peça, isso não faz sentido para mim, nós somos mais do que isso (visita inicial).

Qualquer um pode dançar [...] então tu já desconstruir a ideia de que tem que ser bailarina [...] não é uma dança de performance, não vai ter nada nem uma apresentação, é viver o momento junto [...] perfeccionismo não é estimulado, não que a gente estimule o erro, mas a gente dá liberdade para errar [...] não é a técnica que é o predominante... é uma atividade coletiva de interação, então o mais importante é isso (roda de conversa).

Tais aspectos demonstram uma resistência ao reducionismo do corpo ao indicador biológico, bem como do movimento à performance.

Sob a ótica da vitalidade-energia, conforme relataram as participantes desta pesquisa, as práticas corporais compreendem o sujeito humano em sua complexidade existencial e multidimensionalidade:

O lema da dança: a dança significa nossa vida, a gente pode até errar mas não deve parar [...] têm músicas mais alegres para levantar o astral, mais meditativas, com coreografias um pouco mais dificeis para trabalhar a nossa mente [...] trabalha o corpo e a mente (usuária). 
Quadro 1. Enunciados do conceito de práticas corporais integrativas em elaboração.

\begin{tabular}{|c|c|c|}
\hline $\mathbf{N}$ & Categoria & Enunciado (As práticas corporais integrativas:) \\
\hline 1 & \multirow[t]{12}{*}{ 1-União } & $\begin{array}{l}\text { Apontam para a união/contato/ligação do ser humano consigo mesmo, com as } \\
\text { outras pessoas, com o universo e com o tempo presente. }\end{array}$ \\
\hline 2 & & $\begin{array}{l}\text { São práticas de meditação em movimento, ou seja, possuem característica } \\
\text { introspectiva/interiorização. }\end{array}$ \\
\hline 3 & & $\begin{array}{l}\text { Visam um trabalho de si para si, mesmo que feitas em grupo, pois propõem que a } \\
\text { pessoa olhe para si, observe, perceba, conecte-se e concentre-se em si mesmo. }\end{array}$ \\
\hline 4 & & $\begin{array}{l}\text { Apontam o vínculo das pessoas entre si, a importância de perceber o outro e estar } \\
\text { em sintonia. }\end{array}$ \\
\hline 5 & & $\begin{array}{l}\text { Externam uma preocupação de que as pessoas percebam sua união com o universo, } \\
\text { entendido como a natureza, a terra e outros elementos que perdemos contato; o que } \\
\text { está a sua volta, o mundo a sua volta e as atividades que o cercam; ou o Eu superior. }\end{array}$ \\
\hline 6 & & $\begin{array}{l}\text { Indicam a consciência no momento presente, com a mente concentrada no que está } \\
\text { fazendo, no agora, na presença, sendo possível esquecer o que está fora, ou uso da } \\
\text { respiração como âncora; bem como a impermanência. }\end{array}$ \\
\hline 7 & & $\begin{array}{l}\text { Ofertam uma visão complexa, ampliada, integral sobre a vida, entendida também } \\
\text { como consciência plena. }\end{array}$ \\
\hline 8 & & $\begin{array}{l}\text { Ligam a realização do exercício, o compartilhamento do momento, ver sentimentos, } \\
\text { olhar outras pessoas. }\end{array}$ \\
\hline 9 & & $\begin{array}{l}\text { Apresentam como finalidade principal o autoconhecimento, por meio do } \\
\text { conhecimento do corpo na sua concepção ampliada (conhecer, entender, sentir, } \\
\text { perceber o corpo e o que acontece consigo, assim como sinais e sintomas) e saber o } \\
\text { que precisa, podendo favorecer o autocuidado, autonomia e empoderamento. }\end{array}$ \\
\hline 10 & & $\begin{array}{l}\text { Partem de uma concepção ampliada de corpo, em oposição à ideia de um corpo } \\
\text { fragmentado (peça por peça), considerando que somos um todo, expresso em } \\
\text { várias dimensões: corpo e mente; físico e emocional; corpo, mente e espírito; corpo, } \\
\text { mente e emoções; astral, mente, corpo e alma; cinco corpos: físico, emocional, } \\
\text { mental, corpo de crença e corpo de prazer ou bem-aventurança; o que sinto, o que } \\
\text { penso e aquilo manifestado no meu corpo. }\end{array}$ \\
\hline 11 & & $\begin{array}{l}\text { Apresentam formas de compreender a anatomia e fisiologia do corpo a partir das } \\
\text { visões ocidental e oriental. }\end{array}$ \\
\hline 12 & & $\begin{array}{l}\text { Buscam promover sensação de plenitude, prazer, de valer a pena aquele momento, } \\
\text { sendo esta uma forma de expressão/materialização/vivência da ideia de conexão. }\end{array}$ \\
\hline 13 & \multirow[t]{8}{*}{ 2-Grupo } & São feitas em grupo. \\
\hline 14 & & São realizadas em grupos heterogêneos em idade e condições de saúde/doença. \\
\hline 15 & & $\begin{array}{l}\text { São realizadas em grupos abertos, ou seja, qualquer pessoa pode participar, pode } \\
\text { entrar/sair a qualquer tempo. }\end{array}$ \\
\hline 16 & & $\begin{array}{l}\text { São inclusivas, pois propõem/adaptam movimentos que todos possam fazer, não } \\
\text { precisa ter experiência prévia com a prática para participar e cada um é orientado a } \\
\text { fazer dentro de suas condições. }\end{array}$ \\
\hline 17 & & $\begin{array}{l}\text { Promovem no grupo interação, integração, união (unir as pessoas, unir problemas } \\
\text { e possíveis soluções), vínculo; é viver com, viver o momento junto, trabalhar juntos, } \\
\text { estar em sintonia. Ali se constroem amizades, uma família e derivam outros grupos } \\
\text { para outras atividades. O grupo é uma oportunidade das pessoas se conhecerem, se } \\
\text { enturmarem, espaço de se encontrar, conversar, trocar ideias, sentir-se querido, com } \\
\text { carinho e acolhimento. No grupo tem contato físico constante, sentir o outro, tocar } \\
\text { o outro. }\end{array}$ \\
\hline 18 & & $\begin{array}{l}\text { Nem sempre promovem interação no grupo, pois não propiciam contato com } \\
\text { outras pessoas da turma. O trabalho meditativo é tu contigo mesmo. O exercício é } \\
\text { individual, mesmo compartilhando o mesmo espaço e os mesmos movimentos. }\end{array}$ \\
\hline 19 & & $\begin{array}{l}\text { Estimulam a sensação de pertencimento à comunidade; curar-se no espaço em que } \\
\text { nasceu, em que vive e desenvolve suas relações; e permitem conhecer o bairro. }\end{array}$ \\
\hline 20 & & As pessoas querem aumentar o grupo, chamam outras pessoas. \\
\hline
\end{tabular}


Quadro 1. Enunciados do conceito de práticas corporais integrativas em elaboração.

\begin{tabular}{|c|c|c|}
\hline $\mathbf{N}$ & Categoria & Enunciado (As práticas corporais integrativas:) \\
\hline 21 & \multirow[t]{5}{*}{ 3-Cotidiano } & Estão ancoradas em uma certa filosofia de vida “aplicável” no cotidiano. \\
\hline 22 & & $\begin{array}{l}\text { Possibilitam aprendizados (se aprende muito, aprendi a me concentrar, a pensar, a } \\
\text { trabalhar a impermanência, a fazer em casa, a dançar, a conhecer a cultura musical } \\
\text { de cada país), que as pessoas levam para o cotidiano. }\end{array}$ \\
\hline 23 & & $\begin{array}{l}\text { Contribuem para ressignificar o cotidiano, pois as pessoas levam para a vida o } \\
\text { que aprendem/vivenciam nas práticas, por exemplo: transformar a visão das } \\
\text { coisas, transformar a realidade interna, lidar melhor com as questões da vida, } \\
\text { lidar melhor com as emoções, lidar melhor com a convivência/reflete no convívio, } \\
\text { ajudar as pessoas, ter equilíbrio nas atitudes do dia a dia, mudar discurso das dores/ } \\
\text { problemas para alegria, mudar a postura da queixa. }\end{array}$ \\
\hline 24 & & $\begin{array}{l}\text { Quebram a racionalidade do dia a dia (ritmo de produtividade, aceleração e } \\
\text { exigência) e a rotina (são oportunidades para sair e ver coisas novas). }\end{array}$ \\
\hline 25 & & $\begin{array}{l}\text { Tem eficácia prática na vida das pessoas, pois resolvem problemas sutis e duros do } \\
\text { cotidiano. }\end{array}$ \\
\hline 26 & \multirow[t]{8}{*}{ 4-Saúde/Doença } & Partem de olhares diferentes para a saúde. \\
\hline 27 & & $\begin{array}{l}\text { Entendem a saúde como o encontro consigo mesmo e a sensação de plenitude e } \\
\text { conexão. }\end{array}$ \\
\hline 28 & & $\begin{array}{l}\text { Promovem bem-estar, qualidade de vida, melhoria da saúde/doença e cura em } \\
\text { várias dimensões do ser (melhoras relacionadas à hipertensão, dores, problemas } \\
\text { de coluna, ciático e perna, depressão, dormir melhor; melhora de capacidades e } \\
\text { qualidades físicas como coordenação motora, lateralidade, equilíbrio, alongamento, } \\
\text { memória e concentração; sensaçôs de calma, paciência, relaxamento, alegria, } \\
\text { satisfação, felicidade, sair renovada). }\end{array}$ \\
\hline 29 & & Restabelecem movimentos naturais do corpo. \\
\hline 30 & & Reduzem uso de medicamentos e tabagismo. \\
\hline 31 & & São promotoras e recuperadoras de saúde. \\
\hline 32 & & Estimulam a pessoa a se ver como parte do seu tratamento, do seu remédio. \\
\hline 33 & & Estimulam a pessoa a ir mais fundo do que o imediato no tratamento. \\
\hline 34 & \multirow[t]{8}{*}{ 5-Movimento } & São práticas de movimento corporal. \\
\hline 35 & & Possuem técnicas de movimento variadas. \\
\hline 36 & & $\begin{array}{l}\text { Envolvem movimentos que parecem simples, leves, mas mexem com tudo, mexem } \\
\text { muitos músculos. }\end{array}$ \\
\hline 37 & & $\begin{array}{l}\text { Envolvem movimentos com diferentes ritmos, com repetição, com permanência } \\
\text { ou continuidade, músicas alegres, meditativas e coreografias mais difíceis e } \\
\text { movimentos adaptados. }\end{array}$ \\
\hline 38 & & Equilibram esforço e conforto. \\
\hline 39 & & $\begin{array}{l}\text { Possuem um simbolismo nos movimentos, com sentidos e significados que podem } \\
\text { ser explicados. }\end{array}$ \\
\hline 40 & & $\begin{array}{l}\text { Combinam movimentos com falas e explicações sobre as técnicas, valores e filosofia } \\
\text { da prática. }\end{array}$ \\
\hline 41 & & Associam movimentos com a respiração. \\
\hline 42 & \multirow[t]{4}{*}{ 6-Não é } & $\begin{array}{l}\text { Não são só biológico, físico, exercício físico, movimentos e repetições de } \\
\text { movimentos, só alongar e relaxar. }\end{array}$ \\
\hline 43 & & $\begin{array}{l}\text { Não seguem lógica de aula de ginástica com peso, do corpo fragmentado peça por } \\
\text { peça. }\end{array}$ \\
\hline 44 & & Não exigem perfeccionismo e performance. \\
\hline 45 & & Não forçam a participação das pessoas. \\
\hline
\end{tabular}

continua

A parte física é boa porque vai te ajudar na firmeza mesmo do próprio corpo né, da coluna, das articulações [...] para parte emocional também... é um todo né, o corpo é um todo, nós somos um todo 
Quadro 1. Enunciados do conceito de práticas corporais integrativas em elaboração.

\begin{tabular}{|c|c|c|}
\hline $\mathbf{N}$ & Categoria & Enunciado (As práticas corporais integrativas:) \\
\hline 46 & \multirow{5}{*}{$\begin{array}{l}\text { 7-Energia/ } \\
\text { Espiritualidade- } \\
\text { Religiosidade }\end{array}$} & Trabalham com energia e campos de força. \\
\hline 47 & & Possibilitam a circulação e obtenção de energia. \\
\hline 48 & & $\begin{array}{l}\text { Promovem desenvolvimento pessoal e espiritual, inteligência espiritual, conexão } \\
\text { com o Eu superior e integração corpo-mente-espírito. São uma oportunidade de } \\
\text { evolução espiritual. }\end{array}$ \\
\hline 49 & & $\begin{array}{l}\text { Consideram a espiritualidade, mas não tem cunho religioso, embora respeitem e } \\
\text { acolham quem fala de Deus e sua religião, mas a pessoa pode participar mesmo } \\
\text { sendo ateu e sem acreditar em Deus. }\end{array}$ \\
\hline 50 & & $\begin{array}{l}\text { Envolvem alguns rituais, falas ou movimentos que abordam questões energéticas e } \\
\text { espiritualidade. }\end{array}$ \\
\hline 51 & \multirow[t]{2}{*}{ 8-Ciência } & Acreditam que nem tudo pode ser explicado pela ciência normal. \\
\hline 52 & & São comprovadas cientificamente. \\
\hline 53 & 9- Valores & $\begin{array}{l}\text { Apoiam-se e disseminam valores como: solidariedade, amor em ação, amorosidade, } \\
\text { gratidão, paciência, felicidade, equilíbrio, equalização, além de estimularem } \\
\text { qualidades positivas. }\end{array}$ \\
\hline 54 & \multirow[t]{3}{*}{ 10- Profissional } & $\begin{array}{l}\text { São novas estratégias para dar conta das demandas das comunidades, uma vez que } \\
\text { a prática profissional baseada em protocolos, no modelo biomédico e institucional } \\
\text { é insuficiente. }\end{array}$ \\
\hline 55 & & Satisfazem os profissionais que trabalham com elas. \\
\hline 56 & & $\begin{array}{l}\text { São conduzidas por profissionais elogiados pelas usuárias por serem legais, ótimos } \\
\text { e pelo carinho; mas também criticados porque exercem poder sobre as pessoas } \\
\text { vulneráveis. }\end{array}$ \\
\hline 57 & \multirow[t]{3}{*}{ 11-Acesso } & São acessíveis. \\
\hline 58 & & São gratuitas. \\
\hline 59 & & São ofertadas na esfera pública que deve ser valorizada. \\
\hline 60 & \multirow[t]{2}{*}{ 12-Satisfação } & Satisfazem os profissionais que trabalham com elas. \\
\hline 61 & & $\begin{array}{l}\text { Satisfazem as usuárias, que consideram que participar é bom, muito bom, bom para } \\
\text { a vida, gratificante, maravilhoso, legal e que afirmam que vão porque gostam. }\end{array}$ \\
\hline 62 & \multirow[t]{3}{*}{ 13-Respiração } & Trabalham a respiração. \\
\hline 63 & & Associam os movimentos com a respiração. \\
\hline 64 & & Promovem a conexão com o corpo e o tempo presente por meio da respiração. \\
\hline 65 & 14-Vivência & $\begin{array}{l}\text { Acreditam que a vivência (você não entra para olhar, entra para dançar) possibilita } \\
\text { a compreensão e permanência da pessoa na prática. }\end{array}$ \\
\hline 66 & 15-Origem & $\begin{array}{l}\text { Possuem origens distintas em relação à época, local, criadores/ disseminadores e } \\
\text { racionalidade. }\end{array}$ \\
\hline 67 & \multirow[t]{2}{*}{ 16-Contraindicações } & Não são indicadas para determinadas condições de saúde/doença. \\
\hline 68 & & Possuem técnicas com e sem restrições. \\
\hline 69 & 17-Local & $\begin{array}{l}\text { São praticadas ao ar livre, em espaços da comunidade ou no interior do centro de } \\
\text { saúde. }\end{array}$ \\
\hline \multirow{2}{*}{$\frac{0}{1}$} & \multirow{2}{*}{$\begin{array}{l}\text { 18-Avaliação das } \\
\text { aulas }\end{array}$} & São realizadas por meio de um trabalho coerente, tranquilo, com boa dinâmica. \\
\hline & & $\begin{array}{l}\text { Precisam melhorar em alguns aspectos, como a meditação inicial, professora } \\
\text { substituta, piadinhas e atividade com violão. }\end{array}$ \\
\hline 72 & 19-Centro e Saúde & Possibilitam saber informações do centro de saúde. \\
\hline
\end{tabular}

Fonte: Elaborado pela autora.

[...] olhar para dentro de si [...] eu acho que isso reflete no todo, tá fazendo isso para ti e reflete no convívio com os outros (usuária).

A gente trabalha com o modelo dos cinco koshas, dos cinco corpos [...] compreender o corpo físico, o nosso corpo energético, o corpo emocio- nal, o corpo de crença né... o corpo daquela coisa mais enraizada [...] e o corpo de prazer, o corpo de bem-aventurança, enfim, que seria essa experimentação dessa sensação de plenitude assim né, de conexão, de yoga mesmo [...] o encontro consigo mesmo e com essa sensação, com essa conexão, com 
Quadro 2. Características dos modelos Biomédico X Vitalidade-energia.

\begin{tabular}{|c|c|c|}
\hline & Biomédico & Vitalidade-energia \\
\hline Foco do cuidado & Doença & Sujeito \\
\hline Concepção de corpo & Material, fragmentado em partes & $\begin{array}{l}\text { Integral, considera dimensões física, mental, } \\
\text { emocional, energética, espiritual }\end{array}$ \\
\hline Concepção de saúde & Ausência de doenças & Equilíbrio multidimensional do ser e seu entorno \\
\hline $\begin{array}{l}\text { Concepção de } \\
\text { doença }\end{array}$ & $\begin{array}{l}\text { Problema localizado em alguma } \\
\text { parte do corpo }\end{array}$ & Desequilíbrio da harmonia interna e relacional \\
\hline $\begin{array}{l}\text { Meios para } \\
\text { diagnóstico }\end{array}$ & Exames clínicos e laboratoriais & Técnicas variadas e narrativa das/os usuárias/os \\
\hline $\begin{array}{l}\text { Recursos } \\
\text { terapêuticos }\end{array}$ & $\begin{array}{l}\text { Medicamento, cirurgia, } \\
\text { intervenções externas ao sujeito }\end{array}$ & $\begin{array}{l}\text { Simples e variados, intervenções que reforçam ou } \\
\text { induzem uma resposta natural do organismo }\end{array}$ \\
\hline $\begin{array}{l}\text { Abordagem } \\
\text { terapêutica }\end{array}$ & Parcial, com ênfase no corpo físico & $\begin{array}{l}\text { Holística, com enfoque integral nos problemas de } \\
\text { saúde e da vida }\end{array}$ \\
\hline Custo & Mais onerosas & Menos onerosas \\
\hline $\begin{array}{l}\text { Relação profissional- } \\
\text { usuária/o }\end{array}$ & Impessoal e verticalizada & Estratégica, horizontalizada e humanizada \\
\hline Uso de tecnologias & Duras, leves-duras & Leves, leves-duras \\
\hline Objetivos & $\begin{array}{l}\text { Prevenção de doenças e fatores de } \\
\text { risco e reabilitação da saúde via } \\
\text { tentativa de extinção da doença }\end{array}$ & $\begin{array}{l}\text { Restabelecimento e expansão da vitalidade; } \\
\text { empoderamento, autonomia, promoção, proteção } \\
\text { e reabilitação da saúde }\end{array}$ \\
\hline $\begin{array}{l}\text { Afinidade/Reforço } \\
\text { social }\end{array}$ & Medicalização social & $\begin{array}{l}\text { Compatível a anseios de preservação e } \\
\text { sustentabilidade em seu sentido amplo, nos níveis } \\
\text { biológico, social e natural }\end{array}$ \\
\hline Cosmologia & $\begin{array}{l}\text { Racionalidade instrumental da } \\
\text { medicina moderna }\end{array}$ & $\begin{array}{l}\text { Sistemas culturais orientais e movimentos de } \\
\text { contracultura }\end{array}$ \\
\hline Preocupação central & Doença & Saúde \\
\hline
\end{tabular}

Fonte: Elaborado pela autora.

esse todo, é o estado de saúde [...] integração do que eu sinto, do que eu penso, com aquilo manifestado no meu corpo... então essa integração corpo-mente -espírito (roda de conversa).

Foi bastante falado de consciência plena... na verdade consciência do corpo, da relação do corpo com os demais, da relação do corpo com o mundo e com as atividades que nos cercam... então, gera empoderamento [...] quando a gente tem esse centramento, quando a gente tem essa noção e intenção, a gente consegue ter escolhas né... e parte muito da consciência [...] não tem como desassociar uma coisa da outra [...] conhecimento do corpo [...] controle das emoções [...] diminuição das dores, que muitas vezes está associada também com essa questão emocional [...] liberdade de expressão corporal [...] lateralidade, coordenação, memória [...] contribuições de pertencimento, de integração social [...] solidariedade (roda de conversa).

Tanto o corpo quanto os processos saúde-doença são concebidos nas relações entre as dimensões física, mental, emocional, espiritual e energética, as quais são acionadas simultaneamente quando colocamos o corpo em movimento. Nesse sentido, as propostas de técnicas, baseadas na interiorização, na expressão corporal e no exercício da presença, são meios para o desenvolvimento de um trabalho sensível e reflexivo. Esse trabalho, que tem como unidade integradora a experiência corporal, constitui o principal recurso terapêutico para induzir uma resposta em direção ao reestabelecimento e ampliação da vitalidade.

Além disso, as práticas corporais integrativas apresentam relação com a cultura. As participantes da pesquisa ressaltaram princípios filosóficos e um conjunto de valores que sustentam e se disseminam através das práticas:

A gente traz a filosofia [...] trabalha essas questões de solidariedade, de amor em ação, de conexão consigo e com a natureza... então essa é a base filosófica da dança... então a gente, mesmo não usando essas palavras, a gente trabalha esses elementos com o grupo [...] tem um simbolismo, colocar um centro, identificar que todos estamos na mesma posição, mesma distância do centro, todos são impor- 
tantes [...] as músicas, as coreografias, muitas que têm um lado simbólico, normalmente se explica [...] e toda a relação não é só ali na roda, isso elas levam para a vida (roda de conversa).

Envolvem uma filosofia de vida, uma proposta de interiorização, se conhecer, porque yoga não é só alongar e relaxar [...] você vai ter assim nas Escrituras [...] os ásanas eles são um caminho para meditação né... para pessoa chegar nessa consciência plena, de si, do seu corpo, da sua mente, das suas emoções... então a gente vai colocando falas ali no meio das práticas também para pessoa ficar atenta, trazer bem atenção para respiração, tudo, para não ficar uma coisa assim só exercício físico, aquela questão do não julgar, que não tem essa coisa de competição (roda de conversa).

Trabalhar a conexão, a pessoa consigo mesma [...] a conexão entre as pessoas, perceber a mim mesma e ao outro, e o eu no outro [...] trabalham campos de força e energia, o conectar-se com o Eu superior [...] lidar melhor com as questões da vida... $e$ isso também melhora a saúde (visita inicial).

Eu aprendi a trabalhar essa coisa da impermanência [...] acho que todos nós temos dificuldade de trabalhar essa impermanência, porque a gente quer que as coisas fiquem sempre iguais né, que a gente não tenha perdas (usuária).

Eu era totalmente agitada [...] sabe o que é fazer tudo assim no piloto automático?! [...] eu tava fazendo meditação e depois tava percebendo toda transformação, como eu tava diferente [...] vou tomar meu cafezinho, aí eu sentei e [pausa] ai como é que eu posso dizer, me senti presente! Tô aqui [...] sabe aquela sensação do melhor café da tua vida [... parece que não sou eu, parece que me trocaram (usuária).

A abordagem, portanto, não pode se restringir ao recorte de gestos técnicos "exóticos", mas deve contemplar os componentes cosmológicos e seu enraizamento cultural na organização das aulas. Daí deriva também a valorização do componente transcendental da experiência, que se expressou nas falas sob as formas de energia e espiritualidade, demonstrando outra característica central destas práticas.

As práticas corporais integrativas, ao mobilizarem o corpo denso e os corpos sutis, podem produzir epifanias com impactos também sobre os modos como as pessoas lidam com seus processos saúde-doença. O movimento humano propõe um envolvimento do corpo que aciona dimensões sensíveis - no convite que faz à introspecção, à presença, à expressão e à consciência corporal -, provocando a construção de novos sentidos/significados que podem reverberar no cotidiano dos sujeitos, inclusive contribuindo para o desenvolvimento da autonomia, do empoderamento e do autocuidado.

As análises até aqui empreendidas refletem os significados atribuídos por usuárias e condutoras dos grupos de práticas corporais integrativas que fizeram parte da pesquisa, os quais estão sintetizados no Quadro 1. Diante da riqueza desses achados, o movimento analítico resultou nas seguintes enunciações sobre práticas corporais integrativas:

1) São propostas de cuidado e promoção de saúde que se fundamentam no paradigma da vitalidade-energia.

2) Envolvem movimentos corporais que agregam técnicas de respiração, relaxamento, atitude mental, mobilidade em sequências rítmicas ou posturas de permanência, oriundos de diferentes tradições culturais.

3) Prezam pela introspecção e pela qualidade de presença.

4) Estimulam as pessoas a descobrirem os limites e potencialidades do corpo (nas suas dimensões mais visíveis e mais sutis).

5) Promovem processos individuais, mas que reverberam também na coletividade, na medida em que convidam para a construção de uma nova relação consigo, com os outros e com o universo, para o questionamento e o compartilhamento da vida e para a ressignificação dos processos saúdedoença.

O primeiro enunciado localiza o conceito de práticas corporais integrativas no campo da saúde, apresentando-as como propostas terapêuticas pertinentes às esferas do cuidado e da promoção, com potencialidades para contribuir na resolução de problemas pontuais, bem como na ampliação dos recursos para pessoas e comunidades lidarem com os processos saúde-doença, combinando ações de (auto)cuidado e responsabilidade social pela saúde.

Cabe destacar que a filiação ao paradigma da vitalidade-energia está atrelada à visão vitalista contemporânea, que supera perspectivas animistas anteriores, pois procura integrar a reflexividade humana, elemento central da modernidade. Não se trata, portanto, apenas de reativar antigas práticas místicas, mas de valorizar a mística de um sujeito reflexivo, capaz de compreender o mundo do qual ele é parte integrante e ativa ${ }^{27}$. Contemporaneamente, o paradigma da vitalidade-energia é visto como uma espécie de eco da corrente do vitalismo existente desde a Grécia Antiga $^{28}$, com as atualizações provocadas pelo curso da história. 
O segundo enunciado apresenta as técnicas mais usuais do conjunto de práticas corporais integrativas, sendo que não necessariamente todas precisam estar presentes numa mesma modalidade. O terceiro enunciado demarca elementos identitários, a introspecção e a presença, os quais podem representar, ao mesmo tempo, a intenção, o método e o resultado das experiências.

Os últimos enunciados apresentam os propósitos centrais das práticas corporais integrativas, relacionados à complexidade do conhecimento de si/do próprio corpo - considerando a dimensão densa (física) e as dimensões sutis (energéticas, espirituais, emocionais, mentais) - e das possibilidades de mudanças de percepções e ações dos sujeitos, a partir da ativação da sensibilidade e da reflexividade promovida pelas práticas corporais integrativas, a partir de sua gestualidade, ritualística e princípios éticos e cosmológicos. É por isso que o conceito aborda potenciais de ressignificação, de questionamento, de compartilhamento da vida, de construção de novas relações consigo, com os outros e com o universo, sendo o universo a expressão escolhida para representar/ congregar a natureza e a espiritualidade em alusão à dimensão da transcendência.

De modo geral, estariam contempladas nesse conceito as práticas associadas a outras racionalidades médicas, como o yoga ao Ayurveda e o tai chi chuan à MTC, cujas bases são predominantemente orientais, e aquelas emergentes no ocidente após os anos 1960, como antiginástica, bioenergética, danças circulares e biodança.

Cabe destacar que as modalidades de berço ocidental não se vinculam, necessariamente, à racionalidade biomédica. Há um conjunto de práticas corporais integrativas que se originaram e circulam no ocidente como contraponto àquela lógica, associando-se a um modelo ampliado de saúde, desde que o paradigma da vitalidade-energia seja seu sustentáculo.

Para finalizar a etapa de elaboração dos enunciados, solicitamos às participantes que avaliassem se aquilo que estava escrito (formulação conceitual com cinco enunciados) era capaz de representar o que faziam (as experiências com práticas corporais integrativas):

Reflete tudo que a gente vê aqui dentro, os resultados, o convívio, as diferenças que a gente sente, a vontade de vir [...] não faltou nada (usuária).

São palavras-chaves que você pode colocar num guarda-chuva bem grande [...] pra cada um tem um significado a vida, mas é isso mesmo, a gente tá compartilhando a vida... agora, o que é a minha vida que eu compartilho aqui? Então cada um vai ter um significado do que é esse universo, do que é essa vida... são termos e conceitos totais [...] eu me sinto totalmente representado [...] em termos de texto ele consegue colocar tudo, ele me lembra um pouco, vou exagerar agora... um texto bíblico, ele precisa dessa coisa mais ampla e, assim, você entende o que bate com você, acho que esse teu texto é legal por isso, porque ele tem essa amplitude e cada um vai "nossa, é isso mesmo"... eu tô me vendo nele (usuária).

Nossa, já me dá vontade de sair usando [...] gostei muito de você ter usado palavras como vitalidade, atitude mental, presença, fala de reverberar na coletividade, da nova relação consigo... achei interessante usar nova relação consigo e não autoconhecimento, que é uma palavra que foi muito banalizada [...] e questionamento da vida, porque aprofunda mesmo né, porque deixa de ser uma prática só como atividade física e vem a ser uma atitude bem mais integral e completa (condutora).

Unanimemente, afirmaram que as práticas com as quais se envolvem estavam representadas naquela definição. Reconheceram suas intencionalidades e características, valorizando o fato de o conceito ir além do componente técnico e atribuir sentido de unidade à diversidade das práticas em tela. Algumas questionaram a escolha de termos (universo, compartilhamento da vida, respiração, paradigma e limites) e se propuseram a repensá-los, mas não chegaram a apresentar sugestões. Ao final, a maioria afirmou que a redação captou satisfatoriamente os significados atribuídos e definiu bem o conceito.

\section{O nome escolhido para designar}

A escolha pela designação "práticas corporais integrativas" se justifica, de um lado, pelo fato de o substantivo composto "prática corporal" ser recorrente em documentos oficiais que regulamentam os serviços de saúde e em produções acadêmicas brasileiras. Por outro, em função da abrangência do uso em outras esferas para além da saúde, foi necessário agregar uma adjetivação ("integrativas") para demarcar sua filiação ao campo das PICS.

Além da denominação "Medicina Tradicional e Complementar" adotada pela OMS, os termos "alternativa", "complementar" e "integrativa" também são empregados para diferenciar este modelo do biomédico.

O modelo alternativo é compreendido como incompatível (ao modelo biomédico), numa proposta de substituição de um modelo por outro $^{29}$. No Brasil, "alternativas" é um termo utilizado desde longa data, mas com baixa aceitação no 
contexto institucional da saúde. Ele expressa certa radicalidade e tem sido associado a práticas esotéricas e não comprovadas cientificamente ${ }^{30}$. Já a medicina complementar significa complemento, que sucede ao elementar, havendo a possibilidade de associação de modelos ${ }^{29}$. E o elementar, no caso, são as práticas biomédicas, sendo as PICS consideradas acessórias.

Entretanto, a ideia de complementar é posta em xeque no cotidiano porque, às vezes, as ações em saúde podem ser alternativas, ou seja, não compatíveis com as prescrições biomédicas; outras vezes as práticas biomédicas é que passam a ser complementares ${ }^{30}$. As PICS na Atenção Primária podem ser uma opção de cuidado que antecede os recursos biomédicos típicos (remédios), os quais ficariam reservados para os casos de fracasso ou agravamento da situação ${ }^{31}$. Deste modo, a nomenclatura pretende inscrever o modo como as práticas devem se relacionar com o modelo biomédico, mas as ações nos serviços de saúde eventualmente subvertem tal subordinação.

A expressão "medicina integrativa" surgiu no final dos anos 1990, buscando descrever um novo modelo de saúde que integrasse diversos modelos terapêuticos, mais do que simplesmente operasse com a lógica complementar, e que oferecesse cuidado integral. Para muitos autores, a Medicina Integrativa representa a integração da medicina convencional com a não convencional, oferecendo mais opções de tratamento ao usuário. Para outros, representa uma mudança de paradigma, exigindo mudanças em relação às concepções de saúde, às formas de intervenção no processo saúde-doença e ao modelo de atenção à saúde, algo associado à integralidade do cuidado, humanização das relações, construção de evidências científicas e mudanças na educação em saúde ${ }^{29}$.

A PNPIC optou pela nomenclatura "práticas integrativas e complementares" sem explicitar as razões. Contudo, logo que uma política pública é publicada, entram em cena outros atores sociais para interpretar, operacionalizar e reconfigurar seu conteúdo. O modelo integrativo foi visto como um meio para certos saberes e práticas entrarem no SUS, abriu brechas para o diálogo entre saberes científicos e populares; a compreensão dos sujeitos em relação à multidimensionalidade humana, incluindo a espiritualidade; a significação da integralidade ${ }^{30}$.

Deste modo, além de ser o conceito mais atual, a expressão “integrativas" está alinhada com uma mudança paradigmática. Ela é capaz de congregar os elementos que contemplam os enunciados expostos acima sobre o conceito de práticas corporais, assim como a categoria denominada de conexão, central no percurso investigativo que gerou os enunciados sob a ótica das PICS. A categoria conexão converge com a noção de integrativo, tanto semanticamente quanto epistemologicamente. No primeiro caso porque "conectar" pode ser sinônimo de "integrar", no segundo porque estabelece correlação com o paradigma da vitalidade-energia.

$\mathrm{Na}$ literatura circulam outros termos e definições que dialogam com o que propusemos neste texto. Um deles ${ }^{13}$ define as práticas corporais e meditativas como:

[...] práticas de saúde, exercidas por profissionais de diversas formações e inspiradas em várias racionalidades de saúde, tradições culturais e conhecimentos, que abordam a unicidade do ser através da corporeidade, em contraposição a rupturas dos humanos entre si, com a natureza e consigo mesmos. As características comuns a essas práticas são: [1] a integração entre razão, intuição, sensibilidade e sentidos, de modo a possibilitar distanciamentos momentâneos dos problemas cotidianos $e$ estados de auto-observação com potencial de ampliar a compreensão das ligações entre o que acontece no corpo e suas relações com os outros e com o mundo; [2] a sinergia entre o cuidado terapêutico e a promoção da saúde, o que favorece a atenção a pessoas com condições crônicas; [3] o compromisso com a lógica inclusiva da complementaridade que orienta as PICS e que se expressa no alinhamento dessas práticas aos princípios, políticas e produção do cuidado no $S U S^{13}$ (p.107).

Outro $^{14}$ indica que

as práticas corporais integrativas se caracterizariam por integrar diversos conhecimentos e técnicas corporais que prezam pelo autoconhecimento, sensibilização, propriocepção, atenção, relaxamento, lentidão, suavidade, tendo como propósito o cuidado com as pessoas, com a promoção, manutenção e recuperação da saúde ${ }^{14}$ (p.103).

A noção de conexão também está contemplada, principalmente no primeiro, como uma característica enunciativa frequente, conforme indicam as expressões: [1] integração; [2] sinergia; [3] lógica inclusiva e alinhamento, além da unicidade do ser.

Com relação ao conteúdo, ambos conceitos, assim como nossa proposição, apresentam definições convergentes, porém mais detalhadas, do que as predominantes na literatura internacional. No documento da OMS supracitado ${ }^{1}$, disponível em sete idiomas, as práticas corporais aparecem relacionadas como terapias físicas, mentais e espirituais, associadas aos termos mente-corpo na 
versão francesa (esprit-corps) e inglesa (mind-bo$d y$ ) e psicofísico na espanhola (psicofísicas) e italiana (psicofisiche).

É interessante notar algumas coincidências na literatura nacional e estrangeira sobre a designação dessas práticas, em que pese o contexto de sua presença na Atenção Básica brasileira ter poucos correlatos em outros países. Além do uso como um termo já dado, por vezes é descrito apenas pela exemplificação de modalidades. Em outros casos, está circunscrito aos componentes técnicos - foco mental, controle da respiração e gestualidade corporal - e à indissociabilidade físico-emocional-mental-espiritual no comportamento humano.

Com relação as nomenclaturas, em "práticas corporais e meditativas", o termo "meditativas" pode remeter à prática de meditação em si, como substantivo, e não a um estado (de conexão) que qualifica as práticas, quando usado como adjetivo. Essa denominação guarda alguma relação com "práticas corporais e mentais" e "mind-bodytherapies", presentes em documentos oficiais anteriormente citados.

A expressão "práticas corporais integrativas" foi utilizada em uma política estadual ${ }^{32}$, em um relatório de gestão do $\mathrm{MS}^{33}$ e também figura no âmbito acadêmico ${ }^{14}$. Isto reforça que este termo está, de alguma maneira, circulando nos estratos onde estamos estudando o fenômeno, além de remeter às próprias PICS.

No Glossário Temático de PICS aparecem os termos "práticas corporais da MTC", "práticas expressivas" e "práticas corpo-mente". Quanto aos dois primeiros, os argumentos apresentados até agora sinalizam compatibilidades que permitem a reunião de várias práticas sob o nome "práticas corporais integrativas", incluindo as de tradição chinesa e as associadas às danças. Quanto ao terceiro, similar ao documento da OMS, o uso do hífen parece ser um recurso para ampliar a noção de corpo (indissociável da mente/psique), mas controverso porque declara dualidade. No nosso caso, buscamos alinhamento às PICS através da noção de "integrativo", evitando a fragmentação e apostando numa mudança paradigmática, em favor de uma visão complexa sobre a vida.

\section{Considerações finais}

A proposta deste artigo foi elaborar uma formulação conceitual para "práticas corporais integrativas", tendo desenvolvido uma teoria formal conforme as orientações metodológicas da Grou- nded Theory. Em síntese, tomando como base os três componentes de um conceito, os resultados deste estudo assinalam como desfecho a Figura 3.

O esforço deste trabalho de investigação, ao se deparar com diferentes práticas corporais integrativas em serviços de saúde de Florianópolis-SC, foi buscar convergências entre elas. O movimento de formulação conceitual consistiu no encontro de sentidos de unidade para a diversidade das práticas, capazes de reunir uma série de enunciados comuns a um mesmo nome para representar um recorte específico da realidade.

Se, por um lado, essa opção investigativa tornou possível a escrita de um conceito representativo do conjunto, por outro deixou de fora uma infinidade de outras análises derivadas das peculiaridades de cada prática. Outra ressalva se refere ao desafio de tentar comunicar aspectos de característica oriental dentro de uma estrutura de narrativa ocidental, um limitante presente ao longo de todo trabalho, mas, ao mesmo tempo, o próprio exercício realizado conjuntamente com as informantes da pesquisa.

Já durante os processos de validação de dados, o fato de as usuárias e condutoras dos grupos reconhecerem, unanimemente e sem qualquer contraposição, que a definição proposta contemplava suas experiências foi outro limite do estudo. Além disso, não poder contar com o retorno dos experts externos quanto à formulação conceitual frustrou, de certo modo, expectativas e diminuiu o leque de avaliação. E, ainda, a rotatividade dos grupos ao retornar para essa etapa indicou a provisoriedade dos exercícios de mapeamento e também a dificuldade de fixação de atividades na rotina dos serviços de saúde, com prováveis impactos sobre as comunidades envolvidas e problemas/desafios para as ações de registro e monitoramento das PICS no Brasil.

Por fim, destacamos que o conceito formulado deve ser compreendido em relação ao cenário da investigação, com possibilidades de ser transferido para diferentes contextos, tais como: âmbito acadêmico, serviços de saúde, documentos de políticas públicas. Por mais que as experiências humanas escapem aos enunciados, a designação é o preço que se paga para reconhecermos as coisas do mundo, cuja existência é definida pela linguagem. Nenhum conjunto de palavras é capaz de dizer tudo, mas aquilo que é possível dizer pode lhe propiciar um lugar de existência, sempre a ser revisado e problematizado. O conceito derivado deste estudo, portanto, está lançado, sem qualquer pretensão de controle do seu alcance, e aberto a novos diálogos. 


\section{Recorte da realidade conceituado}

. Conjunto de práticas como lian gong, qi gong, tai chi chuan, lien chi, yoga, danças circulares, biodança, bioenergética, meditação, etc. que acontecem no âmbito do SUS e estão previstas na PNPIC.

\section{Enunciados}

. As práticas corporais integrativas são propostas de cuidado e promoção de saúde que se fundamentam no paradigma da vitalidade-energia e envolvem movimentos corporais que agregam técnicas de respiração, relaxamento, atitude mental, mobilidade em sequências rítmicas ou posturas de permanência, oriundos de diferentes tradições culturais, que prezam pela introspecção e pela qualidade de presença e estimulam as pessoas a descobrirem os limites e potencialidades do corpo (nas suas dimensões mais visíveis e mais sutirs), em processos que são individuais, mas que reverberam na coletividade, na medida em que convidam para a construção de uma nova relação consigo, com os outros e com o universo, para o questionamento e o compartilhamento da vida e para a ressignificação dos processos saúde-doença.

\section{Nome}

. Práticas corporais integrativas

Figura 3. Conceito de práticas corporais integrativas.

Fonte: Elaborada pela autora.

\section{Colaboradores}

PC Antunes trabalhou na concepção e delineamento da pesquisa, na produção e análise de dados e na redação do artigo. AB Fraga trabalhou no delineamento e orientação da pesquisa e na revisão crítica do artigo. 


\section{Referências}

1. World Health Organization (WHO). WHO Traditional Medicine Strategy 2014-2023. Genebra: WHO; 2013.

2. Brasil. Ministério da Saúde (MS). Política Nacional de Práticas Integrativas e Complementares no SUS. Brasília: MS; 2006.

3. Brasil. Ministério da Saúde (MS). Portaria no 849, de 27 de março de 2017. Inclui a Arteterapia, Ayurveda, Biodança, Dança Circular, Meditação, Musicoterapia, Naturopatia, Osteopatia, Quiropraxia, Reflexoterapia, Reiki, Shantala, Terapia Comunitária Integrativa e Yoga à Política Nacional de Práticas Integrativas e Complementares. Diário Oficial da União 2017; 27 mar.

4. Brasil. Ministério da Saúde (MS). Portaria no 702, de 21 de março de 2018. Altera a Portaria de Consolidação no 2/GM/MS, de 28 de setembro de 2017, para incluir novas práticas na Política Nacional de Práticas Integrativas e Complementares. Diário Oficial da União 2018; 21 mar

5. Brasil. Ministério da Saúde (MS). Ampliação da PNPIC [Internet]. 2017 [acessado 2019 mai 27]. Disponível em: http://189.28.128.100/dab/docs/portaldab/documentos/informe_pics_maio2017.pdf.

6. Sousa IMC, Tesser CD. Medicina Tradicional e Complementar no Brasil: inserção no Sistema Único de Saúde e integração com a atenção primária. Cad Saude Publica 2017; 33(1):1-15.

7. Cazarin G, Lima SFF, Benevides IA. Avaliabilidade da Política de Práticas Integrativas e Complementares do município de Recife-PE. J Manag Prim Heal Care 2017; 8(2):203-215.

8. Lima KMSV, Silva KL, Tesser CD. Práticas integrativas e complementares e relação com promoção da saúde: experiência de um serviço municipal de saúde. Interface (Botucatu) 2014; 18(49):261-272.

9. Sousa IMC, Bodstein RCDA, Tesser CD, Santos FDADS, Hortale VA. Práticas integrativas e complementares: oferta e produção de atendimentos no SUS e em municípios selecionados. Cad Saude Publica 2012; 28(11):2143-2154.

10. Antunes PC. Práticas corporais integrativas: experiências de contracultura na Atenção Básica e emergência de um conceito para o campo da saúde [tese]. Porto Alegre: Escola de Educação Física, Fisioterapia e Dança; 2019.

11. Amado DM, Rocha PRS, Ugarte AO, Ferraz CC, Lima MC, Carvalho FFB. Política Nacional de Práticas Integrativas e Complementares no Sistema Único de Saúde 10 anos: avanços e perspectivas. J Manag Prim Heal Care 2017; 8(2):290-308.

12. Brasil. Ministério da Saúde (MS). Glossário Temático: práticas integrativas e complementares em saúde. Brasília: MS; 2018.

13. Galvanese AT. Corporeidade nos grupos de práticas integrativas corporais e meditativas na rede pública de atenção primária à saúde na região oeste do município de São Paulo [tese]. São Paulo: Faculdade de Medicina; 2017.
14. Terra JD. O corpo em experiência nas práticas corporais: o método self-healing de Meir Schneider na atenção à saúde [tese]. São Paulo: Escola de Educação Física e Esporte; 2017.

15. Minayo MCS. O desafio do conhecimento: pesquisa qualitativa em saúde. $11^{\text {a }}$ ed. São Paulo: Hucitec; 2008

16. Dalhberg I. Teoria do conceito. Rev Cien Inform 1978; 7(2):101-107.

17. Charmaz K. A Construção da Teoria Fundamentada: guia prático para análise qualitativa. Porto Alegre: Artmed; 2009.

18. Santos JLG, Cunha KS, Adamy EK, Backes MTS, Leite JL, Sousa FGM. Análise de dados: comparação entre as diferentes perspectivas metodológicas da Teoria Fundamentada nos Dados. Rev Esc Enferm USP 2018; 52:1-8.

19. Luz MT. Novos saberes e práticas em Saúde Coletiva estudos sobre racionalidades médicas e atividades corporais. São Paulo: Hucitec; 2003.

20. Luz MT, Barros NF, organizadores. Racionalidades Médicas e Práticas Integrativas em Saúde: estudos teóricos e empíricos. Rio de Janeiro: CEPESC-IMSUERJ, Abrasco; 2012.

21. Tesser CD. Produção de saber, racionalidades médicas e cuidado: ideias iniciais. In: Nascimento MC Nogueira MI, organizadoras. Intercâmbio solidário de saberes em saúde: racionalidades médicas e práticas integrativas e complementares. São Paulo: Hucitec; 2013. p. 80-105.

22. Tesser CD, Luz MT. Racionalidades médicas e integralidade. Cien Saude Colet 2008; 13(1):195-206.

23. Tesser CD, Luz MT. Uma introdução às contribuições da epistemologia contemporânea para a medicina. Cien Saude Colet 2002; 7(2):363-372.

24. Tesser CD, Luz MT. Uma categorização analítica para estudo e comparação de práticas clínicas em distintas racionalidades médicas. Physis 2018; 28(1):1-23.

25. Sousa IM, Vieira AL. Serviços públicos de saúde e medicina alternativa. Cien Saude Colet 2005; 10(Supl.):255-266.

26. Tesser CD, Barros NF. Medicalização social e medicina alternativa e complementar: pluralização terapêutica do Sistema Único de Saúde. Rev Saude Publica 2008; 42(5):914-920

27. Martins $\mathrm{PH}$. As outras medicinas e o paradigma energético. In: Luz MT, Barros NF, organizadores. Racionalidades Médicas e Práticas Integrativas em Saúde: estudos teóricos e empíricos. Rio de Janeiro: UERJ/IMS/ LAPPIS; 2012. p.309-342.

28. Nascimento MC, Nogueira MI. Concepções de natureza, paradigmas em saúde e racionalidades médicas. Forum Sociol 2014; 24(II):1-15.

29. Otani MAP, Barros NF. A Medicina Integrativa e a construção de um novo modelo de saúde. Cien Saude Colet 2011; 16(3):1801-1811.

30. Toniol R. Do espírito na saúde: oferta e uso de terapias alternativas/complementares nos serviços de saúde pública no Brasil [tese]. Porto Alegre: Instituto de Filosofia e Ciências Humanas; 2015.

31. Tesser CD. Práticas integrativas e complementares e racionalidades médicas no SUS e na atenção primária à saúde: possiblidades estratégicas de expansão. $J \mathrm{Ma}$ nag Prim Heal Care 2017; 8(2):216-232. 
32. Secretaria de Saúde do Estado do Rio Grande do Sul. Politica Estadual de Práticas Integrativas e Complementares. Porto Alegre; 2013.

33. Brasil. Ministério da Saúde (MS). Departamento de Atenção Básica. Coordenação Nacional de Práticas Integrativas e Complementares. Relatório de gestão 2006/2010. Brasília: MS; 2011.

Artigo apresentado em 21/02/2020

Aprovado em 09/07/2020

Versão final apresentada em 11/07/2020

Editores-chefes: Romeu Gomes, Antônio Augusto Moura da Silva 